\title{
Sea-ice freeboard retrieval using digital photon-counting laser altimetry
}

\author{
Sinéad L. FARRELL, ${ }^{1,2,3}$ Kelly M. BRUNT, ${ }^{1,3}$ Julia M. RUTH, ${ }^{4}$ John M. KUHN, ${ }^{2}$ \\ Laurence N. CONNOR, ${ }^{2}$ Kaitlin M. WALSH ${ }^{3,5}$ \\ ${ }^{1}$ Earth System Science Interdisciplinary Center (ESSIC), University of Maryland, College Park, MD, USA \\ E-mail: sineadf@umd.edu \\ ${ }^{2}$ NOAA Laboratory for Satellite Altimetry, College Park, MD, USA \\ ${ }^{3}$ Cryospheric Sciences Branch, NASA Goddard Space Flight Center, Greenbelt, MD, USA \\ ${ }^{4}$ Physics Department, University of Maryland, College Park, MD, USA \\ ${ }^{5}$ Sigma Space Corporation, Lanham, MD, USA
}

\begin{abstract}
Airborne and spaceborne altimeters provide measurements of sea-ice elevation, from which sea-ice freeboard and thickness may be derived. Observations of the Arctic ice pack by satellite altimeters indicate a significant decline in ice thickness, and volume, over the last decade. NASA's Ice, Cloud and land Elevation Satellite-2 (ICESat-2) is a next-generation laser altimeter designed to continue key sea-ice observations through the end of this decade. An airborne simulator for ICESat-2, the Multiple Altimeter Beam Experimental Lidar (MABEL), has been deployed to gather pre-launch data for mission development. We present an analysis of MABEL data gathered over sea ice in the Greenland Sea and assess the capabilities of photon-counting techniques for sea-ice freeboard retrieval. We compare freeboard estimates in the marginal ice zone derived from MABEL photon-counting data with coincident data collected by a conventional airborne laser altimeter. We find that freeboard estimates agree to within $0.03 \mathrm{~m}$ in the areas where sea-ice floes were interspersed with wide leads, and to within $0.07 \mathrm{~m}$ elsewhere. MABEL data may also be used to infer sea-ice thickness, and when compared with coincident but independent ice thickness estimates, MABEL ice thicknesses agreed to within $0.65 \mathrm{~m}$ or better.
\end{abstract}

KEYWORDS: polar and subpolar oceans, remote sensing, sea ice

\section{INTRODUCTION}

Sea-ice mass balance is a leading indicator of the state of the global climate system. Understanding the nature and variability of Arctic and Southern Ocean sea ice is critical to improve predictions of future climate state (NRC, 2012). Altimeters on both airborne and satellite platforms provide measurements of sea-ice elevation, from which sea-ice freeboard and thickness may be inferred (e.g. Laxon and others, 2003; Kwok and Cunningham, 2008; Farrell and others, 2009). By incorporating knowledge of ice concentration, sea-ice volume may be estimated. Thus the ice pack may be monitored remotely, and an assessment of interannual variability and decadal trends in ice thickness and volume may be established.

Observations from the Ice, Cloud and land Elevation Satellite (ICESat), Envisat and CryoSat-2 missions indicate a decline in the thickness and volume of the Arctic ice pack over the past 10 years (e.g. Giles and others, 2008; Kwok and others, 2009; Kurtz and others, 2011; Laxon and others, 2013). The sea-ice pack has changed rapidly in its composition, transitioning from a predominantly thick, multi-year ice pack to a thinner, seasonal pack (Comiso, 2012), and the greatest losses have been observed in the oldest, multi-year ice areas (Farrell and others, 2009). NASA's Operation IceBridge (OIB) mission (Koenig and others, 2010), which commenced in March 2009, includes yearly (every March/April) airborne campaigns over critical regions of the Arctic sea-ice pack, and extends the monitoring provided by satellites. IceBridge provides altimetric measurements of the ice pack at higher resolution ( tens of meters) than the satellite altimeters ( $\sim$ hundreds to thousands of meters). Recent assessment of the IceBridge dataset shows that, following the precipitous drop in multi-year ice in 2007/08 (Giles and others, 2008; Haas and others, 2008; Kwok and others, 2009), the central Arctic remains dominated by multi-year ice just over $3 \mathrm{~m}$ thick, while ice thickness in the Beaufort and Chukchi Seas appears to continue to decline (Richter-Menge and Farrell, 2013).

With the planned launch of ICESat-2 in 2017 we may expect continuity of the sea-ice freeboard, and hence thickness, time series through the end of this decade. Accurate measurement of monthly, basin-scale sea-ice freeboard is a key mission requirement for ICESat-2 (http:// icesat.gsfc.nasa.gov/icesat2/). ICESat-2 data, when combined with observations from previous and ongoing missions (e.g. European Remote-sensing Satellites 1 and 2 (ERS-1/2), Envisat, ICESat, CryoSat-2, IceBridge), will allow us to better understand the evolution of the ice pack over a multi-decadal period. ICESat-2 will carry the Advanced Topographic Laser Altimeter System (ATLAS), which uses a different detection strategy to the Geoscience Laser Altimeter System (GLAS) on ICESat. ATLAS is a high-repetitionrate $(10 \mathrm{kHz})$, multi-beam, $532 \mathrm{~nm}$ wavelength laser that utilizes photon-counting (PC) techniques for surface detection (Abdalati and others, 2010). Specifically, ATLAS will have six laser beams, each with a $\sim 10 \mathrm{~m}$ diameter footprint and $\sim 0.07 \mathrm{~cm}$ along-track sampling, and will measure the range of individual photons returned from the surface. ATLAS beams will be arranged in three sets of beam pairs, with spacing between sets of pairs $\sim 3000 \mathrm{~m}$ apart, while each beam within a given pair will be $\sim 90 \mathrm{~m}$ apart (Brunt and others, 2014). This configuration is primarily designed 


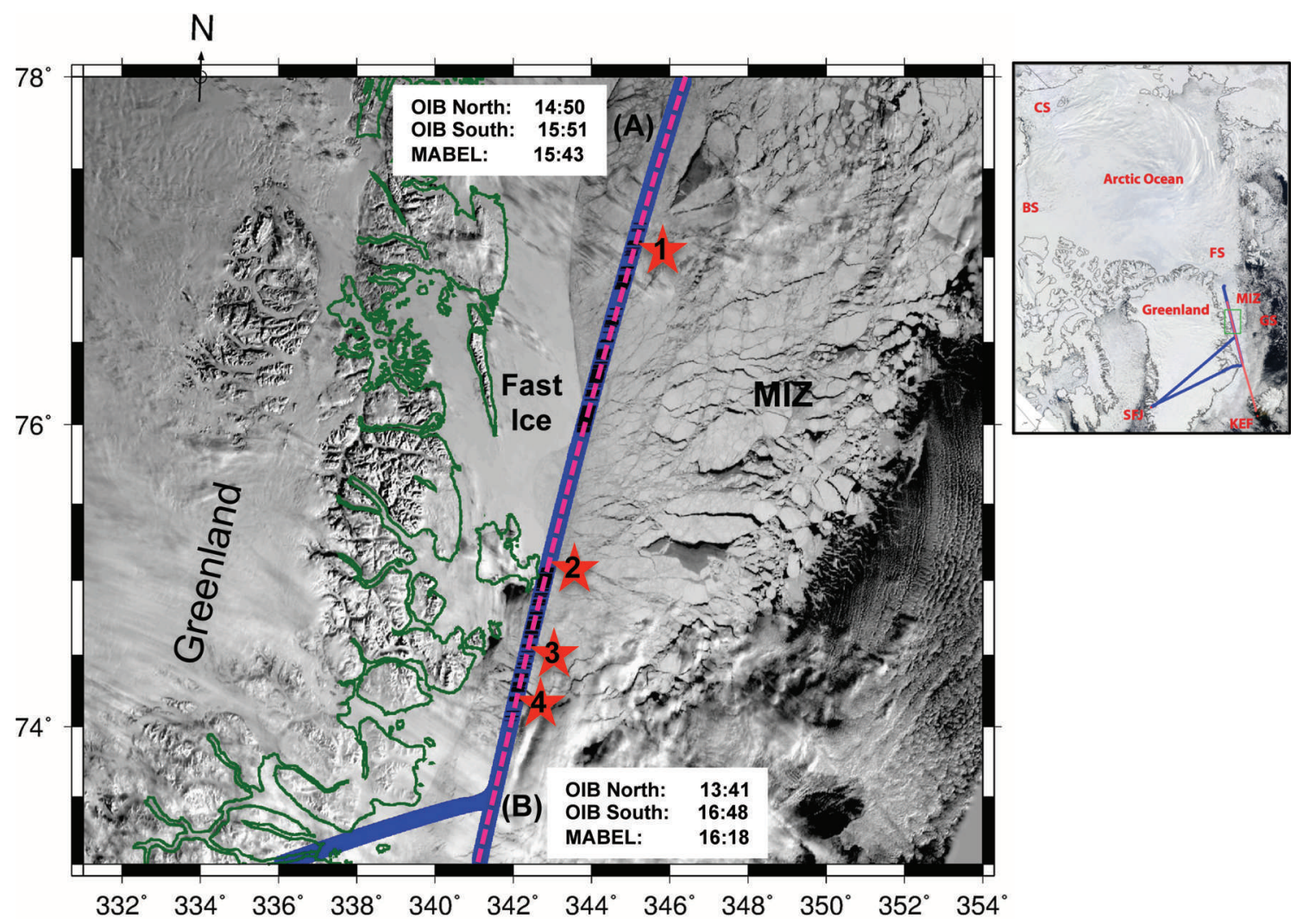

Fig. 1. Map of airborne survey over sea ice in the Greenland Sea conducted on 10 April 2012. Sea-ice conditions are illustrated with a contemporaneous Aqua MODIS image, acquired 6.3 hours before the MABEL survey, and indicate landfast ice along the Greenland coast and large ice floes in the marginal ice zone (MIZ). Blue line shows the trajectory of the NASA P3-B, which conducted the survey, transiting from point (B) to (A) to (B) in an out-and-back loop, at the times indicated. Pink line illustrates the trajectory of the NASA ER-2 survey, which transited from point (A) to (B) in $35 \mathrm{~min}$, at times indicated. Red stars indicate four case-study regions with varying sea-ice conditions. Inset shows Arctic region highlighting the Greenland Sea (GS), Fram Strait (FS), Beaufort Sea (BS) and Chukchi Sea (CS) with an overview of the flight surveys. The P3-B flight was conducted from Kangerlussuaq (SFJ), Greenland, while the ER-2 flight was conducted from Keflavík (KEF), Iceland.

to determine surface slope in areas of high topographic relief on ice sheets, but will also be useful for accurate sea-ice freeboard determination by increasing the number of available elevation measurements across leads.

ICESat-2 offers some considerable improvements compared to its predecessor ICESat, in particular the dense along-track sampling of the surface, which will allow flexibility in the post-processing algorithmic approaches taken to optimize the signal-to-noise ratio and obtain highly detailed measurements of the sea-ice pack (Farrell and others, 2011). With digital PC, uncertainty arises due to not knowing from where within the $10 \mathrm{~m}$ footprint the photon was returned. Exploiting the dense surface sampling, alongtrack averaging is therefore employed to improve measurement accuracy (Abdalati and others, 2010).

Here we demonstrate the utility of digital, micro-pulse PC laser altimetry over the polar oceans for the derivation of sea-ice freeboard. The Multiple Altimeter Beam Experimental Lidar (MABEL) is an airborne simulator for ATLAS (McGill and others, 2013). Although the specifications for MABEL differ slightly from those for ICESat-2 (Kwok and others, 2014), MABEL was designed to test the instrument theory and measurement strategy of ICESat-2. MABEL data are being used to develop geophysical algorithms prior to launch (Brunt and others, 2014). In this study, we assess the quality of the first PC altimetry dataset gathered over the Arctic ice pack, and its usefulness for deriving sea-ice freeboard. We utilize coincident, conventional analogue laser altimetry to determine the accuracy of the novel freeboard estimates derived from MABEL. Utilizing novel snow depth estimates from IceBridge we also assess sea-ice thickness estimates derived from MABEL freeboard data.

\section{DATA}

\subsection{Experiment configuration}

An airborne experiment took place on 10 April 2012, during which the NASA ER-2 aircraft carrying MABEL, and the NASA P-3B aircraft carrying the IceBridge instrument suite (http://icebridge.gsfc.nasa.gov), surveyed sea ice in the Greenland Sea, south of Fram Strait (Fig. 1). Sea-ice conditions in the area (illustrated in a contemporaneous Moderate Resolution Imaging Spectroradiometer (MODIS) image acquired $\sim 6.3$ hours before the MABEL survey; Fig. 1) included landfast ice along the Greenland coast and large ice floes in the marginal ice zone (MIZ). The P-3B surveyed the region by transiting northbound (from point (B) to (A), Fig. 1) at $\sim 460 \mathrm{~m}$ above the ice and returned from point (A) to $(\mathrm{B})$ at $\sim 915 \mathrm{~m}$, measuring a wider swath of ice on the southbound leg. The ER-2 aircraft overflew the P-3B at $\sim 18000 \mathrm{~m}$ at the northern end of the track, and, for operational reasons, only collected data on its return leg from (A) to (B). The weather along the survey line varied, with cloud and low-level ice fog north of point $(A)$ and south of point (B), while the central part of the line had clear-sky conditions. These weather conditions were verified using near-coincident MODIS imagery 


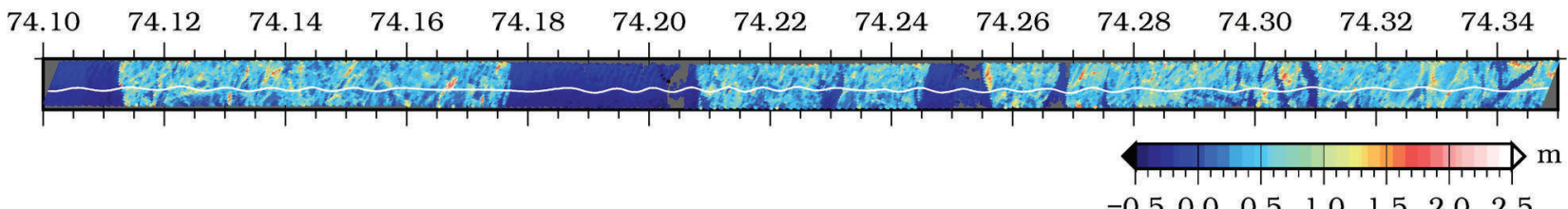

$\begin{array}{lllllll}-0.5 & 0.0 & 0.5 & 1.0 & 1.5 & 2.0 & 2.5\end{array}$
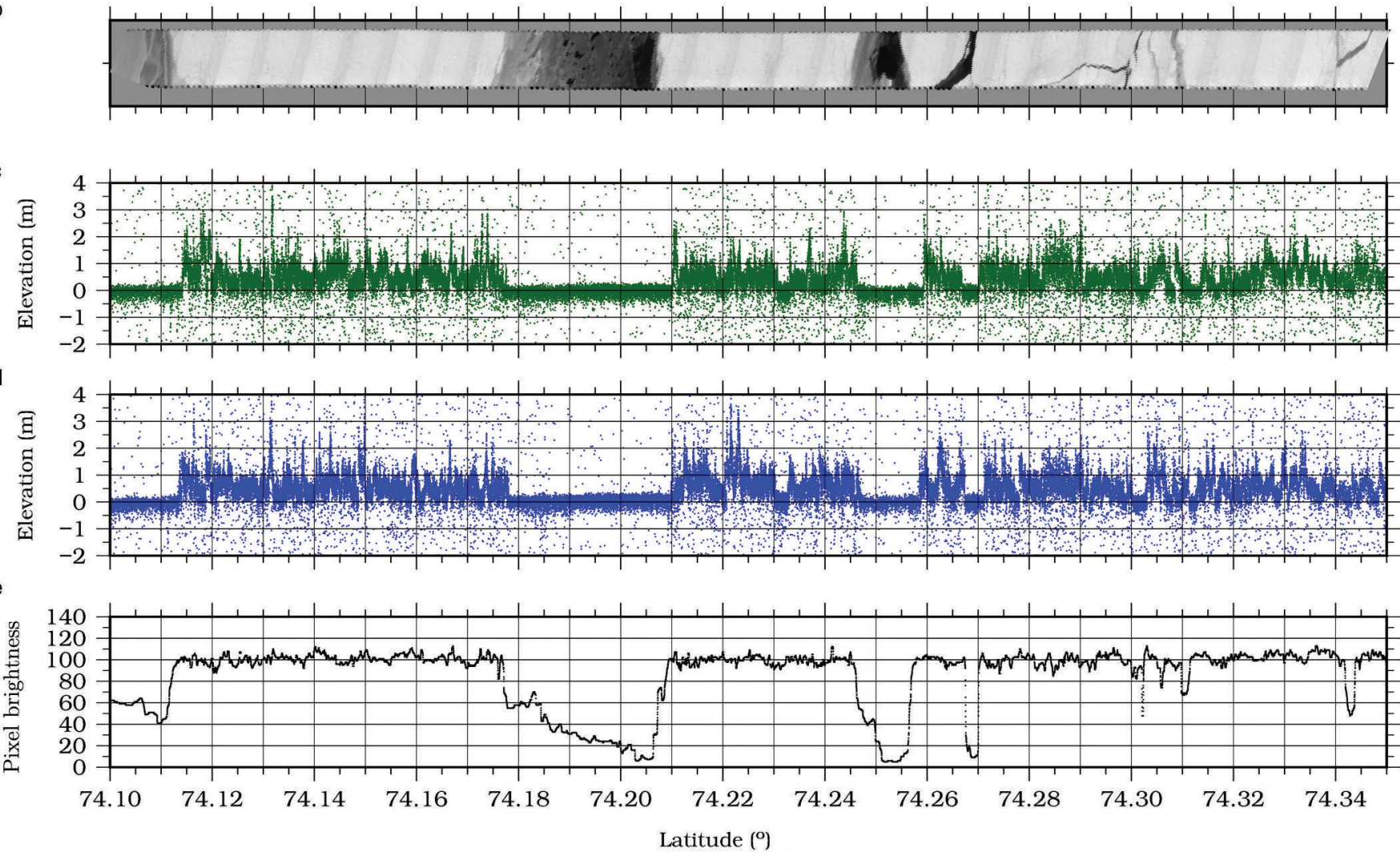

Fig. 2. Sea-ice elevation and morphology at the southern end of the survey in case-study region 4 (see Fig. 1 for location). (a) ATM elevation swath map with MABEL beam 6 geolocation (white line); (b) DMS imagery; (c) raw MABEL elevation profile, beam 6; (d) raw MABEL elevation profile, beam 5; and (e) DMS pixel brightness. Elevations are quoted with respect to the geoid, and geophysical and drift corrections have been applied.

and data collected by the Cloud Physics Lidar (http://cpl.gsfc. nasa.gov/), a second instrument flown on the ER-2. This study focuses on an assessment of MABEL data quality at four locations (Fig. 1, red stars) between points (A) and (B), via comparison with data from two IceBridge instruments: the Airborne Topographic Mapper (ATM) laser altimeter (Krabill, 2013) and the Digital Mapping System (DMS) high-resolution camera (Dominguez, 2010). Data assessed in each study region (Fig. 1, red stars) span $\sim 28 \mathrm{~km}$ and represent a wide variety of sea-ice types.

\subsection{Airborne data}

The ATM airborne laser altimeter operates at a wavelength of $532 \mathrm{~nm}$ with a pulse repetition frequency of $5 \mathrm{kHz}$ and a scan angle of $\sim 15^{\circ}$. Depending on flight altitude during the survey, the $\mathrm{P}-3 \mathrm{~B}$ mapped elevations across a swath, ranging from approximately 250 to $575 \mathrm{~m}$. For a nominal flight altitude, the footprint size was $\sim 1 \mathrm{~m}$ and footprint separation at the swath center was typically $\sim 5 \mathrm{~m}$ in the alongtrack direction. The ATM digitizes returned energy as a waveform, from which surface elevation is derived (Fig. 2a). Here we utilize the IceBridge ATM Level-1B Elevation and Return Strength (ILATM1B) dataset (Krabill, 2013). Elevation measurements were interpolated onto a regular $10 \mathrm{~m}$ grid using a near-neighbor routine.
We also make use of the DMS L1B Geolocated and Orthorectified Images (IODMS1B) dataset, which consists of high-resolution natural color imagery with a pixel resolution of $\sim 0.1 \mathrm{~m}$ (Dominguez, 2010). The DMS images are useful for interpreting sea-ice features (Fig. 2b), and pixel brightness (intensity) may be used for lead discrimination (Fig. 2e). Here we interpolated the DMS data onto a regular $10 \mathrm{~m}$ grid.

MABEL is a PC laser altimeter with multiple beams arranged in a linear array, perpendicular to the direction of flight, operating at two wavelengths: 1064 and $532 \mathrm{~nm}$. MABEL beams have variable signal strengths and the system allows for beam geometry changes between flights if required. In this study we assess MABEL release 8 data from beams 6 and 5, which are two $532 \mathrm{~nm}$ wavelength beams, located at the center of the linear array and at $\sim 85 \mathrm{~m}$ (ground spacing) away from the center, respectively (Brunt and others, 2014). We assessed beams 5 and 6 since, for this flight, they are most similar to the expected radiometry of the strong beams on ATLAS, itself a $532 \mathrm{~nm}$ wavelength laser (Brunt and others, 2014). During this experiment the pulse repetition frequency of the MABEL laser was $5 \mathrm{kHz}$, such that for a nominal aircraft speed of $\sim 200 \mathrm{~m} \mathrm{~s}^{-1}$, a $\sim 2$ m diameter footprint was illuminated every $\sim 0.04 \mathrm{~m}$ along-track (Brunt and others, 2014). Raw, unfiltered MABEL data collected over the ice pack include signal photons reflected from the 


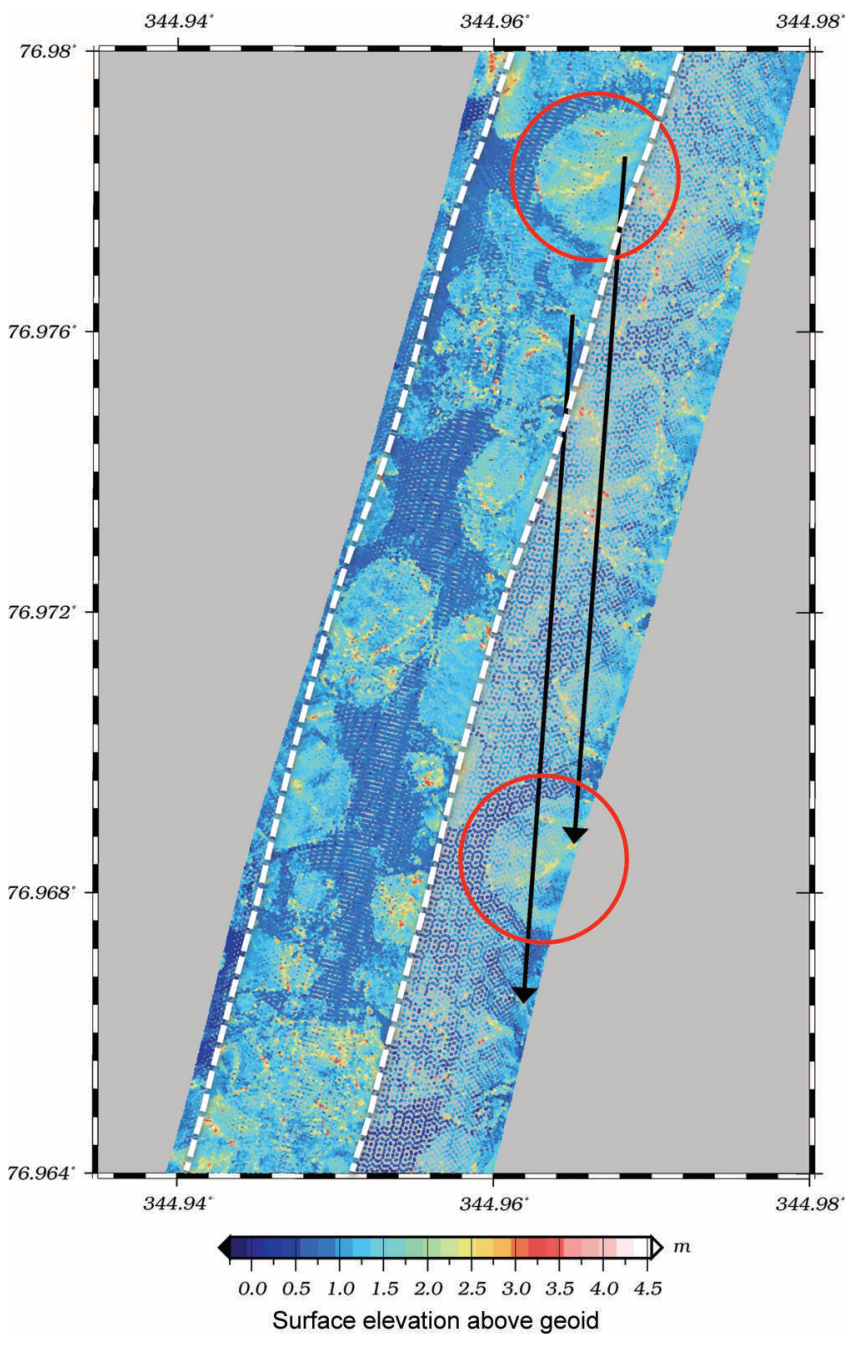

Fig. 3. Swaths of sea-ice elevation, derived from the ATM laser altimeter, for the northbound (bounded by dashed white line) and southbound legs of the IceBridge sea-ice survey on 10 April 2012. Local ice-drift vectors (black arrows) were estimated by manually tracking the geolocation of features in the sea-ice pack (e.g. red circles indicate a deformed sea-ice floe).

sea-ice/ocean surface, and background photons due to solar backscatter in the atmosphere and detector noise. For this flight $\sim 4.3$ signal photons per meter along-track were recorded for beams 5 and 6 (Brunt and others, 2014). An absolute elevation bias correction was applied to the MABEL data, following Brunt and others (2014), to account for differences in the optical paths, unique to each MABEL beam. For beam 5 the bias correction was $1.99 \mathrm{~m}$, while it was $1.76 \mathrm{~m}$ for beam 6 . Figure 2c and d show MABEL alongtrack measurements for beams 6 and 5, respectively, and indicate signal photons close to the surface and background photons dispersed in the atmospheric column.

\subsection{Geophysical corrections}

The Earth Gravitational Model 2008 (EGM2008; Pavlis and others, 2008) was subtracted from all altimetric elevation measurements (ATM and MABEL) to provide surface height above the geoid. The GOT 4.8 ocean tide correction was applied to remove the effects of local tides during the time frame of the experiment and includes a long-period equilibrium ocean tide correction to remove tidal effects due to the Sun (Ray, 1999).

\subsection{Sea-ice drift correction}

Since each NASA aircraft operated at different flight speeds, there was a shift in temporal sampling between the two airborne surveys. High rates of sea-ice drift are encountered south of Fram Strait and this complicates assessment of data gathered by the two aircraft systems in this region. To achieve accurate intercomparisons we must therefore account for ice velocity. We estimate and correct for the local sea-ice drift rate by comparing the geolocation of specific sea-ice features (e.g. pressure ridges and rubble fields) in the northbound and southbound ATM elevation swaths (Fig. 3). Velocity vectors were computed to correct for the temporal offset between the IceBridge and MABEL data. We estimate an average drift rate of $0.25 \mathrm{~m} \mathrm{~s}^{-1}$, which agrees to within $0.01 \mathrm{~m} \mathrm{~s}^{-1}$ with an independent estimate of sea-ice drift on the date of the experiment, derived from a combined Advanced Scatterometer and Special Sensor Microwave/ Imager product available at CERSAT/Ifremer (http://cersat. ifremer.fr/). Combining knowledge of the drift rate, and the time elapsed between MABEL and IceBridge acquisitions, we adjusted the geolocation of the MABEL data to coincide with the ATM and DMS data.

\section{METHODS}

We apply the MABEL surface-finding algorithm outlined in Brunt and others (2014), a histogram-based approach for distinguishing signal photons from background photons, to reduce the MABEL point cloud such that it only includes the coarse signal photons associated with sea-ice and ocean surface returns (Fig. 4a). We apply a one-dimensional (1-D) along-track maximum likelihood probability filter, operating at $10 \mathrm{~m}$, to the MABEL data to further reduce noise and smooth the surface response of the lidar (Fig. 4b) to achieve consistency in the spatial sampling of both the MABEL and IceBridge datasets.

Data from the laser altimeters assessed in this study provide measurements of both sea-ice and lead elevations. For ice floes, the primary reflection is from the air/snow interface via surface scattering. Sea-ice freeboard, the portion of an ice floe above local sea level, is therefore defined here as the ice-plus-snow freeboard. Accurate identification of leads between floes is required to obtain measurements of the sea-surface height ( $\mathrm{SSH}$, also known as 'tie points'). DMS visible imagery, spatially coincident with both MABEL and ATM, was assessed. Normalized pixel brightness (0-255) at each point along the lidar beam-path was extracted (Fig. 2e). Using a pixel-brightness threshold range of $0-50$ to classify leads, we flag signal photon reflections from lead surfaces (Fig. 4b, light-green dots). We identify ATM lead elevation measurements in the same way (Fig. 4c, orange dots). The threshold value for lead classification was derived empirically, based on close visual inspection of the imagery, and was chosen to include open water, nilas and thin grey ice, while excluding refrozen leads with snow accumulation. Here, modal lead elevation defines the local SSH and was linearly interpolated between tie points to estimate along-track SSH in each $28 \mathrm{~km}$ study region (Fig. $4 \mathrm{~b}$ and $\mathrm{c}$, red lines). Along-track $\mathrm{SSH}$ is subtracted from sea-ice elevation measurements to derive sea-ice freeboard.

To demonstrate the denser along-track surface sampling afforded by digital PC altimetry, we indicate a set of simulated surface elevations assuming the ICESat configuration 

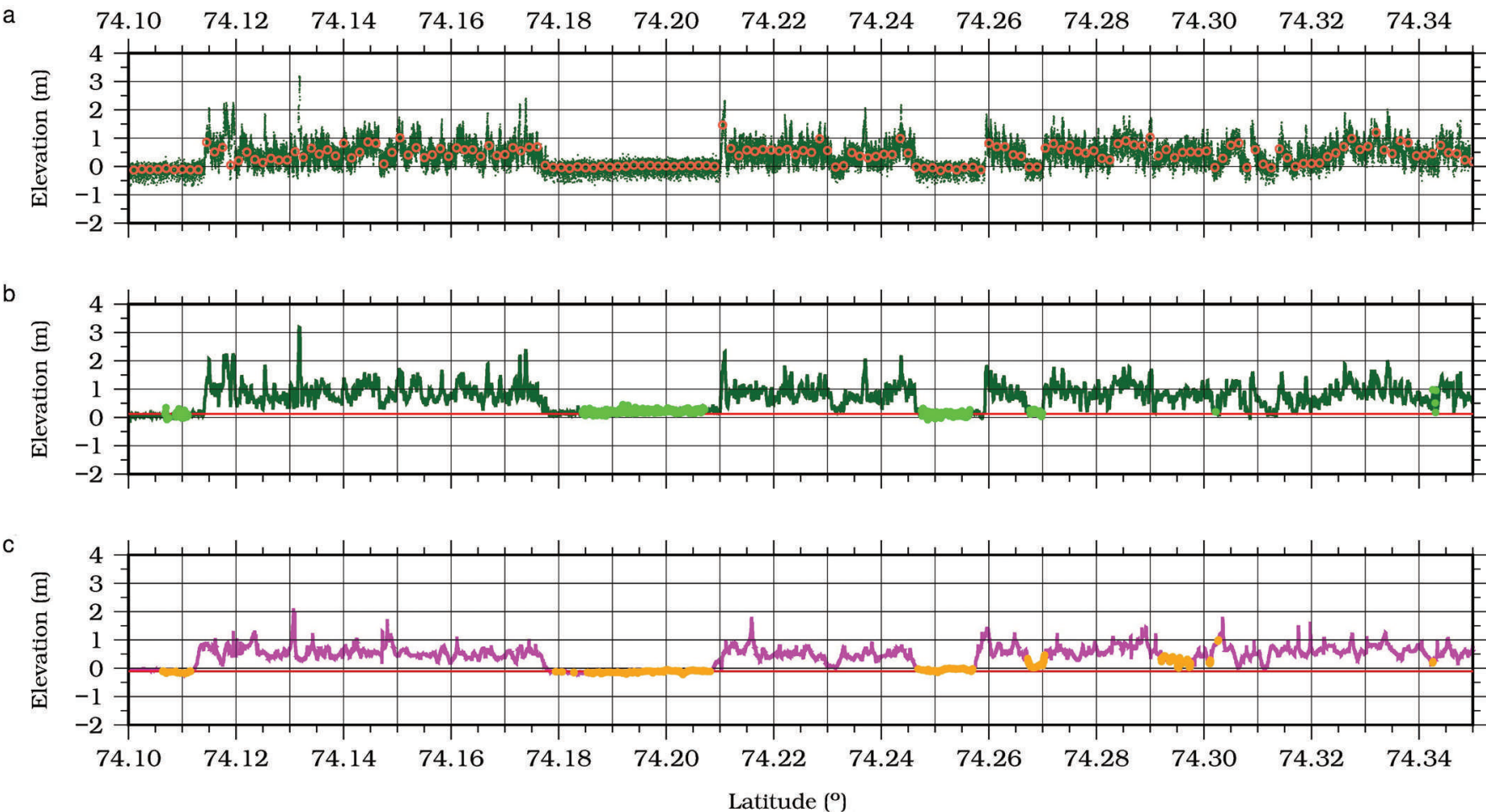

Fig. 4. Sea-ice elevation measured along-track in case-study region 4. (a) MABEL elevations from beam 6, after application of surface-finding algorithm. (b) Same as for (a), after application of $10 \mathrm{~m}$ along-track filter. (c) ATM elevation profile. Lighter-color dots (light-green (b) and orange (c)) indicate the location, and height, of lead elevation measurements, after application of lead discrimination threshold derived from DMS imagery (Fig. 2e). Red line (b, c) indicates sea surface height, interpolated along-track. Open red circles (a) indicate a set of simulated surface elevations assuming the ICESat sampling configuration. Segment shown is $\sim 28 \mathrm{~km}$ long.

(Fig. 4a, open red circles). The GLAS on ICESat consisted of a single-beam laser altimeter with a $\sim 50-70 \mathrm{~m}$ footprint diameter, spaced every $\sim 172 \mathrm{~m}$ along-track (Farrell and others, 2009). Following the approach outlined in Farrell and others (2011) we sampled the MABEL surface elevations using the ICESat/GLAS footprint pattern, recording the mean elevation per footprint using a $50 \mathrm{~m}$ diameter search radius. Application of the MABEL surface-finding algorithm (Brunt and others, 2014) across the $28 \mathrm{~km}$ long segments assessed here resulted in $\sim 75000$ surface elevation measurements, which reduced to $\sim 3200$ measurements after application of the 1-D $10 \mathrm{~m}$ along-track filter. The ICESat sampling approach would have provided only $\sim 170$ elevation measurements across the same distance.

\subsection{Measurement accuracy}

The single-shot accuracy of the ATM elevation measurements is $\sim 0.1 \mathrm{~m}$ (Krabill and others, 2002), and geolocation accuracy is estimated at $1 \mathrm{~m}$ (Schenk and others, 1999). Interpolation of ATM data onto a regular grid results in an elevation precision of $\sim 0.05 \mathrm{~m}$ over level, undeformed sea ice (Farrell and others, 2012). The accuracy of the MABEL elevation measurement is affected by geolocation-induced elevation uncertainty, time-tag errors within MABEL, and errors in the surface-finding algorithm. For sea-ice floes with low surface slope, MABEL elevation uncertainty is estimated at $\sim 0.15 \mathrm{~m}$ (Brunt and others, 2014). Brunt and others (2014) note that while MABEL elevation uncertainty is larger than that of other airborne lidars, it is within the instrument design specifications for ATLAS algorithm development. Assessing the standard deviation of elevation measurements over nilas and new, level sea ice in leads, we also determine a MABEL elevation precision of $0.15 \mathrm{~m}$, consistent with the results of Brunt and others (2014). This further reduces to $0.04 \mathrm{~m}$, after application of the $10 \mathrm{~m}$ along-track filter.

\section{RESULTS}

We assessed sea-ice elevation measurements acquired by both the MABEL and ATM instruments at four case-study locations along the airborne survey line (Fig. 1, red stars). These four $\sim 28 \mathrm{~km}$-long segments were associated with a wide range of sea-ice conditions, outlined in Table 1. After filtering, the MABEL elevation data reveal fine details of the surface roughness and pressure ridging of Arctic sea ice undergoing export through the Fram Strait, while leads and nilas are also well defined (e.g. Fig. 4b). We find strong agreement between the sea-ice morphological features identified in the MABEL data (Fig. 4b) and those revealed in the ATM surface elevation measurements (Fig. 4c) and in the DMS imagery (Fig. 2b).

We derived sea-ice freeboard distributions for case-study regions 1, 3 and 4, comparing freeboard estimates derived from MABEL beams 5 and 6 with freeboard derived from the ATM data. Study area 2 did not contain any leads except for sparse fractures. Thus neither freeboard nor thickness could be determined in case-study region 2, and statistics describing the elevation distribution are provided instead. Freeboard distributions for regions 1, 3 and 4 are shown in Figure 5. Mean and modal freeboard statistics are presented in Table 1. Overall we found good agreement in the form of the derived freeboard distributions for both MABEL and ATM data in all study regions. The bimodal distributions represent the SSH (lower mode) and the sea-ice freeboard (upper 

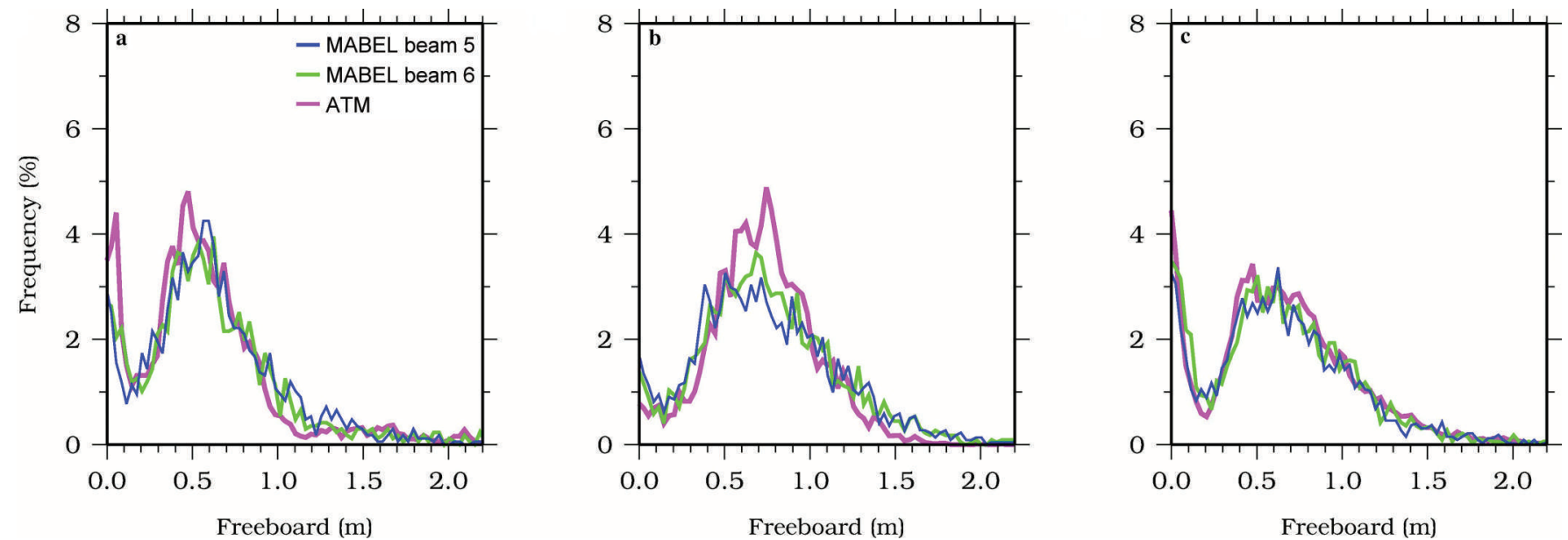

Fig. 5. Sea-ice freeboard distributions for case-study regions 1 (a), 3 (b) and 4 (c). Results are shown for MABEL beam 6 (green), beam 5 (blue) and IceBridge ATM (magenta). Bin size is $0.03 \mathrm{~m}$.

mode), while the elongated tails indicate the presence of thick, deformed ice floes in the survey area. Mean MABELderived freeboard agreed with mean ATM-derived freeboard to $\pm 0.07 \mathrm{~m}$ across all study regions. The best agreement $( \pm 0.03 \mathrm{~m})$ was found in study region 3 , which was composed of discrete floes with pressure ridges and rubble, interspersed with wide leads. Modal freeboard values were typically lower than mean freeboard values and varied by $0-0.15 \mathrm{~m}$ across instruments and study regions. In the region where no leads were present (case study 2), we find that the application of geophysical range corrections (Section 2.3) and the application of the MABEL bias correction for beams 5 and 6 (Section 2.2) provided mean surface elevations consistent to within $0.09 \mathrm{~m}$ or better.

Combining the derived MABEL and ATM freeboards with novel snow depth estimates available from IceBridge, we estimate the thickness of sea ice in case-study regions 1,3 and 4. Thickness may be inferred from altimetric measurements by assuming hydrostatic equilibrium, estimates for the density of snow, ice and sea water, and combining ice freeboard with knowledge of snow depth. Here we calculate mean sea-ice thickness following Giles and others (2007, eqn 2). Separately, data from the full IceBridge instrument suite are processed and released within 6 months of each IceBridge field campaign. These data are used to derive seaice products including freeboard, thickness and snow depth (Kurtz and others, 2013a) that are publicly available via the US National Snow and Ice Data Center (NSIDC). Here we assess the quality of sea-ice thicknesses derived from the retrieved MABEL and ATM freeboards via a comparison with the independently derived IceBridge thickness product (IDCSI2; Kurtz and others, 2012) for 10 April 2012. In order to make an appropriate comparison we follow the values used by Kurtz and others (2013a, and references therein), for

Table 1. Mean sea-ice freeboard and thickness estimates derived from MABEL and ATM elevation measurements for each study region. Modal freeboard results are based on the distributions provided in Figure 5 using a bin size of $0.03 \mathrm{~m}$. A description of sea-ice morphology and atmospheric conditions in each study region is provided. Snow and sea-ice thickness provided in the IceBridge sea-ice product are included for comparison with estimates from MABEL and ATM

Case-study area

Sea-ice conditions

Atmospheric conditions Mean sea-ice freeboard* (m)

Modal sea-ice freeboard* $(\mathrm{m})$

Mean snow thickness (m) Mean sea-ice thickness (uncertainty) (m)
Ice floes with pressure ridges and narrow refrozen leads

$\begin{array}{cc}\text { Clear } & \text { Clear } \\ 0.55 & 0.89 \\ 0.57 & 0.95 \\ 0.6 & 0.98 \\ 0.53 & 0.85 \\ 0.475 \pm 0.015 & 0.825 \pm 0.015 \\ 0.625 \pm 0.015 & 0.925 \pm 0.015 \\ 0.575 \pm 0.015 & 0.875 \pm 0.015 \\ 0.24 & 0.23 \\ 3.60(0.60) & - \\ 3.79(0.53) & - \\ 4.07(0.53) & - \\ 3.97(0.61) & 6.09(0.76)\end{array}$

Discrete floes with pressure ridges and rubble, interspersed with wide leads Clear 0.72 0.75 0.73 0.73

$0.750 \pm 0.015$

$0.700 \pm 0.015$

$0.725 \pm 0.015$ 0.28

$4.94(0.60)$

$5.22(0.53)$

$5.04(0.53)$

$5.29(0.71)$
Discrete floes with pressure ridges and rubble, interspersed with wide leads Clear 0.62 0.58 0.55 0.57

$0.475 \pm 0.015$

$0.625 \pm 0.015$

$0.625 \pm 0.015$ 0.24

$4.29(0.60)$

$3.92(0.53)$

$3.64(0.53)$

$4.15(0.63)$

*Neither sea-ice freeboard nor thickness could be estimated in study region 2 due to a lack of leads. Surface elevation statistics are provided instead. 
the density of snow, ice and sea water. Snow thickness (Table 1) is taken directly from the IceBridge product (Kurtz and others, 2013a). Mean sea-ice thickness for ATM and MABEL beams 5 and 6 is provided in Table 1 and can be compared to the independently derived mean ice thickness estimate provided in the IceBridge product for the same study region. The sea-ice thickness estimates from MABEL and ATM are on average within $0.37 \mathrm{~m}$ of each other and these are in turn consistent with the IceBridge product. Average sea-ice thickness in the Greenland Sea study area is $4.25 \mathrm{~m}$, and independent thickness estimates differ by $0.07-0.65 \mathrm{~m}$.

Sea-ice thickness uncertainty estimates are also provided in Table 1. Following Giles and others (2007, eqn 4) an error propagation analysis is utilized to estimate thickness uncertainty assuming the following terms: The uncertainty associated with the IceBridge snow thickness is $0.057 \mathrm{~m}$ as provided in the product and described by Kurtz and others (2013a). The uncertainty associated with an individual ATM freeboard estimate is equated to the measurement precision of $\sim 0.05 \mathrm{~m}$ for interpolated ATM data over level, undeformed sea ice. Likewise the uncertainty associated with an individual MABEL freeboard estimate is equated to the measurement precision of $\sim 0.04 \mathrm{~m}$ for MABEL data over refrozen leads after the application of the $10 \mathrm{~m}$ along-track filter (Section 3.1). The differences between independent ice thickness estimates fall within the uncertainty for each instrument/product, which ranges from 0.53 to $0.76 \mathrm{~m}$.

\section{SUMMARY AND CONCLUSIONS}

We have demonstrated that MABEL digital, micro-pulse PC laser altimetry data are effective for reliably determining the freeboard and thickness of Arctic sea-ice floes, when combined with auxiliary information on snow depth and snow/ice density. The surface-finding algorithm efficiently distinguished coarse signal from background photons to allow assessment of elevation measurements associated with both ice floes and leads. The surface finder tracked the surface of both rough sea-ice floes and smoother lead surfaces, providing unprecedented details of the surface morphology of Arctic sea ice. We have verified the accuracy of the MABEL freeboard estimates through comparison with independent, coincident measurements collected by the ATM laser altimeter on board IceBridge. The results show that the surface elevation and freeboard distributions derived from the two independent airborne lidar sensors (MABEL and ATM) are consistent. The ATM- and MABEL-derived sea-ice freeboard estimates agreed to within $0.07 \mathrm{~m}$ or better across all study areas, and consistent freeboard estimates $(0.03 \mathrm{~m}$ or better) were derived in study region 3 where deformed ice floes were separated by wide leads. We have also demonstrated that MABEL data may be used to successfully infer seaice thickness. MABEL ice thickness estimates when compared with coincident data from the ATM and the IceBridge thickness product agreed to within $0.65 \mathrm{~m}$ or better.

Although sea-ice freeboard is a differential measurement, knowledge of absolute range is required to define the precision and overall quality of PC elevation measurements of the ice pack. Measurements across undeformed areas of sea ice (e.g. nilas and new ice in leads, level ice pans or level snowfields on fast ice) could be used to calibrate the laser signal, calculate measurement precision, assess the impact of along-track sampling and filtering and investigate potential geophysical range biases due to volume scattering at the surface. In this study, the assessment of MABEL digital PC data quality and accuracy was greatly enhanced by the 'out and back' flight-loop conducted by the IceBridge aircraft. This survey configuration constrained the local ice-drift vectors and allowed rectification of the two airborne datasets to a common reference time frame to mitigate the temporal offset between MABEL and IceBridge acquisitions. The airborne experiment conducted on 10 April 2012 serves as an excellent template for future MABEL missions aimed at assessment of photon-counting laser altimeters over sea ice and provides a demonstration of techniques that could be used to validate ATLAS measurements collected by ICESat-2 over the global sea-ice packs after launch. To assess MABEL/ ATLAS digital PC data, a second altimeter with sufficient accuracy and across-track spatial sampling (i.e. scanning/ swath mapping) is desirable so as to capture the multi-beam MABEL and ATLAS beam configurations. In the case of ATLAS, the central beam pair will be separated by $\sim 90 \mathrm{~m}$, while two outer beam pairs will each be $\sim 3000 \mathrm{~m}$ from the central beam pair (fig. 1 in Brunt and others, 2014).

Further work will include an assessment of additional MABEL data gathered over sea ice during the April 2012 flight campaign and data from future sampling campaigns aimed at obtaining data under different seasonal and atmospheric conditions. The goal for future MABEL seaice deployments is to collect measurements that will support the development of operational algorithms for the retrieval of sea-ice geophysical parameters from ATLAS on ICESat-2 (Kwok and others, 2014). Following the analysis presented in this study, we will investigate an automated approach for deriving sea-ice freeboard estimates from MABEL data that are specifically designed for use in the MIZ. This would take advantage of measurements across numerous lead surfaces that provide plentiful SSH tie points. We will explore the feasibility of producing a set of 'quick look' sea-ice freeboard estimates from ICESat-2 measurements in the MIZ, similar to the quick-look sea-ice products provided as part of the IceBridge mission (Kurtz and others, 2013 b). This could provide information on sea-ice freeboard and thickness in an area of primary interest to the operational sea-ice community.

\section{ACKNOWLEDGEMENTS}

The views, opinions, and findings contained in this report are those of the authors and should not be construed as an official National Oceanic and Atmospheric Administration or US Government position, policy or decision. The authors thank two anonymous reviewers for helpful comments. We acknowledge the considerable efforts of the Project, Science and Instrument Teams of NASA's ICESat-2, MABEL and OIB missions for their collection, processing and dissemination of the remote-sensing data utilized in this study. MABEL data and documentation are available at http://icesat.gsfc.nasa. gov/icesat2/data/mabel/mabel_docs.php. IceBridge data utilized in this study are archived at the NSIDC: the IceBridge ATM Level-1B Elevation and Return Strength (ILATM1B) dataset is available at http://nsidc.org/data/ilatm $1 \mathrm{~b} . \mathrm{html}$, the DMS L1B Geolocated and Orthorectified Images (IODMS1B) dataset is available at http://nsidc.org/data/ iodms 1b.html, and the IceBridge Sea Ice Freeboard, Snow Depth, and Thickness (IDCSI2) dataset is available at http:// nsidc.org/ data/idcsi2.html. This work was supported under NASA Cryospheric Sciences grant NNX12AH28G. 


\section{REFERENCES}

Abdalati $W$ and 16 others (2010) The ICESat-2 laser altimetry mission. IEEE Proc., 98(5), 735-751 (doi: 10.1109/ JPROC.2009.2034765)

Brunt KM, Neumann TA, Walsh KM and Markus T (2014) Determination of local slope on the Greenland Ice Sheet using a multibeam photon-counting Lidar in preparation for the ICESat-2 Mission. IEEE Geosci. Remote Sens. Lett., 11(5), 935-939 (doi: 10.1109/LGRS.2013.2282217)

Comiso JC (2012) Large decadal decline of the Arctic multiyear ice cover. J. Climate, 25(4), 1176-1193 (doi: 10.1175/JCLI-D-1100113.1)

Dominguez R (2010) IceBridge DMS L1B geolocated and orthorectified images (IODMS1B, 2012). NASA Distributed Active Archive Center, National Snow and Ice Data Center, Boulder, CO http://nsidc.org/data/iodms $1 \mathrm{~b} / \mathrm{html}$

Farrell SL, Laxon SW, McAdoo DC, Yi D and Zwally HJ (2009) Five years of Arctic sea ice freeboard measurements from the Ice, Cloud and land Elevation Satellite. J. Geophys. Res., 114(C4), C04008 (doi: 10.1029/2008JC005074)

Farrell SL, Markus T, Kwok R and Connor L (2011) Laser altimetry sampling strategies over sea ice. Ann. Glaciol., 52(57 Pt 1), 69-76 (doi: 10.3189/172756411795931660)

Farrell SL and 9 others (2012) A first assessment of IceBridge snow and ice thickness data over Arctic sea ice. IEEE Trans. Geosci. Remote Sens., 50(6), 2098-2111 (doi: 10.1109/TGRS.2011. 2170843)

Giles KA and 8 others (2007) Combined airborne laser and radar altimeter measurements over the Fram Strait in May 2002. Remote Sens. Environ., 111(2-3), 182-194 (doi: 10.1016/j.rse. 2007.02.037)

Giles KA, Laxon SW and Ridout AL (2008) Circumpolar thinning of Arctic sea ice following the 2007 record ice extent minimum. Geophys. Res. Lett., 35(22), L22502 (doi: 10.1029/ 2008GL035710)

Haas C, Pfaffling A, Hendricks S, Rabenstein L, Etienne J-L and Rigor I (2008) Reduced ice thickness in Arctic Transpolar Drift favors rapid ice retreat. Geophys. Res. Lett., 35(17), L17501 (doi: 10.1029/2008GL034457)

Koenig L, Martin S, Studinger M and Sonntag J (2010) Polar airborne observations fill gap in satellite data. Eos, 91(38), 333-334 (doi: 10.1029/2010EO380002)

Krabill WB (2013) IceBridge ATM L1B elevation and return strength, Version 1 (ILATM1B 2012). NASA Distributed Active Archive Center, National Snow and Ice Data Center, Boulder, CO http://nsidc.org/data/ilatm1b.html

Krabill WB and 8 others (2002) Aircraft laser altimetry measurement of elevation changes of the Greenland ice sheet: technique and accuracy assessment. J. Geodyn., 34(3-4), 357-376 (doi: 10.1016/S0264-3707(02)00040-6)
Kurtz NT, Markus T, Farrell SL, Worthen DL and Boisvert LN (2011) Observations of recent Arctic sea ice volume loss and its impact on ocean-atmosphere energy exchange and ice production. J. Geophys. Res., 116(C4), C04015 (doi: 10.1029/ 2010JC006235)

Kurtz N, Studinger MS, Harbeck J, Onana V and Farrell S (2012, updated 2014) IceBridge sea ice freeboard, snow depth, and thickness. NASA Distributed Active Archive Center, National Snow and Ice Data Center, Boulder, CO http://nsidc.org/data/idcsi2

Kurtz NT and 8 others (2013a) Sea ice thickness, freeboard, and snow depth products from Operation IceBridge airborne data. Cryosphere, 7(4), 1035-1056 (doi: 10.5194/tc-7-1035-2013)

Kurtz $\mathrm{N}$ and 6 others (2013b) IceBridge airborne survey data support Arctic sea ice predictions. EOS, 94(4), 41 (doi: 10.1002/ 2013EO040001)

Kwok R and Cunningham GF (2008) ICESat over Arctic sea ice: estimation of snow depth and ice thickness. J. Geophys. Res., 113(C8), C08010 (doi: 10.1029/2008JC004753)

Kwok R, Cunningham GF, Wensnahan M, Rigor I, Zwally $\mathrm{HJ}$ and $\mathrm{Yi}$ D (2009) Thinning and volume loss of the Arctic Ocean sea ice cover: 2003-2008. J. Geophys. Res., 114(C7), C07005 (doi: 10.1029/2009JC005312)

Kwok R and 8 others (2014) Profiling sea ice with a multiple altimeter beam experimental Lidar (MABEL). J. Atmos. Ocean. Technol., 31(5), 1151-1168 (doi: 10.1175/JTECH-D-13-00120.1)

Laxon S, Peacock N and Smith D (2003) High interannual variability in sea ice thickness in the Arctic region. Nature, 425(6961), 947-950 (doi: 10.1038/nature02050)

Laxon SW and 14 others (2013) CryoSat-2 estimates of Arctic sea ice thickness and volume. Geophys. Res. Lett., 40(4), 732-737 (doi: 10.1002/grl.50193)

McGill M, Markus T, Scott VS and Neumann T (2013) The Multiple Altimeter Beam Experimental Lidar (MABEL): an airborne simulator for the ICESat-2 Mission. J. Atmos. Ocean. Technol., 30(2), 345-352 (doi: 10.1175/JTECH-D-12-00076.1)

National Research Council (NRC) (2012) Seasonal-to-decadal predictions of Arctic sea ice: challenges and strategies (2012). National Academies Press, Washington, DC

Pavlis NK, Holmes SA, Kenyon SC and Factor JK (2008) An Earth gravitational model to degree 2160: EGM2008. Geophys. Res. Abstr., 10 [EGU2008-A-01891]

Ray RD (1999) A global ocean tide model from TOPEX/Poseidon altimetry/COT99.2. (NASA Tech. Rep. NASA/TM-1999209478). NASA Goddard Space Flight Center, Greenbelt, MD

Richter-Menge JA and Farrell SL (2013) Arctic sea ice conditions in spring 2009-2013 prior to melt. Geophys. Res. Lett., 40(22), 5888-5893 (doi: 10.1002/2013GL058011)

Schenk T, Csatho BM and Lee DC (1999) Quality control issues of airborne laser ranging data and accuracy study in an urban area. Int. Arch. Photogramm. Remote Sens., 32(3/W14), 101-108 